\title{
Resistência de genótipos de batata a Meloidogyne javanica(1)
}

\begin{abstract}
João Maria Charchar(2) e Antônio Williams Moita(2)
Resumo - A resistência de 48 genótipos de batata brasileiros e europeus à infecção por Meloidogyne javanica foi avaliada em campo naturalmente infestado, em época seca e chuvosa, no Distrito Federal. O delineamento experimental foi o de blocos casualizados, com quatro repetições e parcelas com dez plantas. Na época seca (maio a setembro), os níveis de infecção em tubérculos comerciais foram de, no máximo, $9,7 \%$, com as temperaturas do solo variando de $13,5^{\circ} \mathrm{C}$ a $27,7^{\circ} \mathrm{C}$. Na época chuvosa (novembro a março), os níveis de infecção por $M$. javanica variaram de $31,0 \%$ a $93,5 \%$ em tubérculos de batata em solo com temperaturas mais elevadas, de $27,0^{\circ} \mathrm{C}$ a $33,0^{\circ} \mathrm{C}$. 'Achat', com maior grau de resistência a $M$. javanica entre os 48 genótipos de batata avaliados, apresentou porcentagem de infecção de tubérculos comerciais de $1 \%$ na época seca e de, no máximo, $31 \%$ na época chuvosa.
\end{abstract}

Termos para indexação: Solanum tuberosum, resistência a pragas, nematóides.

Resistance of potato genotypes to Meloidogyne javanica

\begin{abstract}
The resistance of 48 Brazilian and European potato genotypes to infection by Meloidogyne javanica was evaluated in a naturally infested field, in the dry and rainy seasons in the Federal District, Brazil. The experimental design was the complete randomized block with four replicates and plots with ten plants. In the dry season (May to September), the infection levels on the marketable tubers reached up to $9.7 \%$, with the soil temperatures ranging from $13.5^{\circ} \mathrm{C}$ to $27.7^{\circ} \mathrm{C}$. The levels of infection varied from $31.0 \%$ to $93.5 \%$ in the rainy season (November to March), under higher soil temperatures ranging from $27.0^{\circ} \mathrm{C}$ to $33.0^{\circ} \mathrm{C}$. 'Achat' behaved as the most resistant to $M$. javanica among the 48 potato genotypes, and presented percentages of infection on the marketable tubers of $1 \%$ in the dry season and $31.0 \%$ in the rainy season.
\end{abstract}

Index terms: Solanum tuberosum, pest resistance, nematode.

\section{Introdução}

Meloidogyne javanica (Treub) Chitwood, 1949, é o segundo nematóide das galhas em ordem de importância que causa perda qualitativa à cultura da batata (Solanum tuberosum L.) depois de M. incognita (Kofoid \& White) Chitwood,1949, (Charchar, 1981). Meloidogyne javanica foi encontrado em $37,0 \%$ das amostras de tubérculos infectados por nematóides do gênero Meloidogyne, enquanto M. incognita foi encontrado em $48,0 \%$ das amostras,

\footnotetext{
(1) Aceito para publicação em 19 de janeiro de 2001.

(2) Embrapa-Centro Nacional de Pesquisa de Hortaliças, Caixa Postal 0218, CEP 70359-970 Brasília, DF.

E-mail: charchar@cnph.embrapa.br, moita@cnph.embrapa.br
}

nas regiões produtoras do Brasil (Charchar, 1997). Observou-se, também, que $M$. javanica foi mais rápido em ocupar os sítios de alimentação em raízes e tubérculos de batata, do que M. incognita. As galhas nos tubérculos, resultantes do ataque por M. javanica, foram maiores, mais elevadas e menos coalescentes que as provocadas por M. incognita (Charchar \& Moita, 1997). A associação de M. javanica com M. incognita, nos últimos cinco anos, foi constatada em $15 \%$ das amostras de batata e de outras hortaliças, como batata-doce, cenoura, mandioquinha-salsa e tomate, coletadas na região Centro-Oeste. A infecção simultânea dessas duas espécies foi mais severa quando comparada com a infecção isolada, mesmo na cultivar Achat, que possui resistência moderada a M. incognita a M. javanica (Charchar, 1995; Charchar \& Moita, 1996, 1997). M. javanica 
pode causar até $100 \%$ de perdas em áreas de produção de batata, dependendo da cultivar, da época de plantio, e do nível de infestação do solo (Charchar, 1995).

Como medidas de controle de $M$. javanica, a rotação de culturas e o controle químico são as alternativas mais utilizadas (Zem et al., 1982). Os nematicidas Carbofuran e Aldicarb são os mais utilizados no controle do nematóide em batata. Porém, são produtos altamente tóxicos e com capacidade de acumulação residual nos tubérculos quando aplicados na amontoa da batata (Charchar, 1995).

As cultivares de batata plantadas no Brasil são, na maioria, européias, desenvolvidas em condições climáticas diferentes, e que não apresentam resistência aos nematóides das galhas em condições brasileiras. $\mathrm{O}$ uso da resistência genética em batata para reduzir os níveis populacionais de $M$. javanica é prática de grande importância na redução de uso de produtos químicos (Greco, 1993; Weingartner et al., 1993).

O objetivo deste trabalho foi identificar fontes de resistência em 48 genótipos de batata à infecção por M. javanica em condições de campo naturalmente infestado.

\section{Material e Métodos}

Os experimentos foram conduzidos em área do campo experimental da Embrapa-Centro Nacional de Pesquisa de Hortaliças, em Brasília, DF, em Latossolo Vermelho-Claro $(10,8 \%$ de areia, $19,2 \%$ de silte, $70,0 \%$ de argila e $\mathrm{pH} 5,9)$.

A área experimental, de $20 \times 100 \mathrm{~m}$, foi cultivada com quiabeiro cultivar Santa Cruz 47, em espaçamento de $0,50 \times 0,50 \mathrm{~m}$, antes do plantio de batata. Inocularam-se, em cada plântula de quiabeiro aos 30 dias de idade, 1.000 ovos e juvenis de segundo estádio (J2) de $M$. javanica por planta, para a infestação de toda a área. A parte aérea do quiabeiro foi eliminada, 120 dias após o plantio, e as raízes infectadas foram desenterradas, trituradas e reincorporadas ao solo, com o auxílio de arado e grade, no período menos quente da manhã. O experimento de batata foi instalado logo após a incorporação das raízes de quiabeiro na área, utilizando-se parcelas de $0,80 \times 3,50 \mathrm{~m}$ para o cultivo de dez plantas de cada genótipo a ser avaliado. O delineamento experimental utilizado foi o de blocos casualizados, com quatro repetições. Manteve-se a distância de $0,5 \mathrm{~m}$ entre parcelas e de $1,0 \mathrm{~m}$ entre blocos, e as áreas entre blocos foram mantidas com vegetação natural.

Foram avaliados 48 genótipos de batata quanto à resistência a $M$. javanica; destes, nove foram brasileiros
(Aracy, Baronesa, Chiquita, Clone 27, Clone 70, Clone 88, Mantiqueira, Mineira e Santo Amor), 17 holandeses (Alpha, Anosta, Bintje, Desirée, Diamant, Duvira, Edzina, Elvira, Gloria, Hertha, Monalisa, Nicola, Podzola, Recent, Renska, Vittorini e Vokal), 12 alemães (Achat, Belladona, Berolina, Christa, Culpa, Granola, Grata, Grandifolia, Linda, Nordstern, Univita e Steffi), 4 suecos (Delta-S, JatteBintje, Maria e Sabina), 4 poloneses (Lenino, Sowa, Tarpan e Uran) e 2 franceses (Claudia e Eureka). O experimento conduzido na época seca (maio a setembro) foi repetido na época chuvosa (novembro a março).

Foram aplicados $300 \mathrm{~g}$ de NPK 10-10-10 por metro de sulco como adubo básico, e $100 \mathrm{~g}$ de sulfato de amônio por metro de sulco, 30 dias após o plantio dos genótipos, na amontoa, em cobertura. Não foi aplicado nenhum nematicida nos experimentos de época seca e chuvosa, para não interferir no processo de seleção de fontes de resistência em genótipos de batata à infecção por M. javanica.

Utilizou-se a irrigação por aspersão, e a temperatura do solo na área experimental foi monitorada através de termógrafo automático, com o sensor enterrado a $20 \mathrm{~cm}$ de profundidade

As estimativas populacionais do nematóide no solo foram determinadas de subamostras de $200 \mathrm{~mL}$ de solo, obtidas de amostras de $2 \mathrm{~kg}$, coletadas de cinco pontos distintos por parcela, a uma profundidade de $20 \mathrm{~cm}$, depois da eliminação do quiabeiro (população inicial=Pi), e durante a colheita dos genótipos de batata (população final=Pf), após o ciclo vegetativo de 110 dias. A extração de nematóides do segundo estádio juvenil (J2) de amostras de $200 \mathrm{~mL}$ de solo foi feita por métodos combinados de flutuação, sedimentação e peneiramento (Flegg \& Hooper, 1970), e a separação, por centrífuga, em solução de açúcar (Jenkins, 1964). O fator de reprodução (FR) do nematóide foi determinado pela relação $\mathrm{Pf} / \mathrm{Pi}$ por parcela, para o monitoramento da infestação da área por M. javanica.

A avaliação da infecção de cada genótipo foi baseada na presença de galhas em tubérculos, com a separação de três classes: peso de tubérculos comerciais com galhas; peso de tubérculos comerciais sem galhas e peso de tubérculos não comerciais ou refugo.

Foi feita a somatória dos valores correspondentes aos pesos de tubérculos comerciais com galhas, e sem galhas para a determinação da produção total de tubérculos comerciais, por parcela. A porcentagem de peso de tubérculos com galhas foi determinada pela razão entre o valor correspondente ao peso de tubérculos com galhas e produção total de tubérculos comerciais por parcela, multiplicado por 100 .

Foi aplicada a análise multivariada, método de médias com distância Euclidiana, utilizando o modelo estatístico de Sokal \& Michener (1958), para separação de grupos 
distintos de batata com resistência ou suscetibilidade a M. javanica. A caracterização da resistência foi baseada na infecção de tubérculos por comparação das porcentagem de peso de tubérculos comerciais com galhas (Charchar \& Moita, 1996, 1997).

\section{Resultados e Discussão}

Com a temperatura do solo a $20 \mathrm{~cm}$ de profundidade variando entre $13,5^{\circ} \mathrm{C}$ e $27,5^{\circ} \mathrm{C}$, as relações $\mathrm{Pf} / \mathrm{Pi}$ (fator de reprodução do nematóide $=\mathrm{FR}$ ) nas parcelas com os genótipos variaram de 2 nas cultivares Christa, Mineira, Monalisa e Recent a 33 na cultivar Diamant, que não diferiram estatisticamente, indicando a infestação de toda a área por $M$. javanica após o cultivo de quiabeiro por 120 dias, no experimento de época seca (Tabela 1). Na mesma época seca, a produção de tubérculos variou de 3,5 t/ha na cultivar Edzina a 17 t/ha no Clone 70 (Tabela 1). A baixa produtividade das cultivares importadas deveu-se, provavelmente, à falta de adaptabilidade às condições de cultivo no Distrito Federal; as cultivares nacionais produziram de 7 a 17 t/ha, com média de produção de $12 \mathrm{t} / \mathrm{ha}$, próxima da produção nacional de 12 a 14 t/ha. Foram observados também níveis baixos de infecção de tubérculos comerciais, de, no máximo, 9,7\% na cultivar Vittorini, e de $8,9 \%$ na cultivar Grandifolia, 7,3\% na cultivar Eureka e 7,0\% na cultivar Gloria. A infecção de tubérculos nos demais genótipos variou de 0 (zero) a 5,8\%, e não foi observada diferença significativa (Tabela 1).

Os fatores de reprodução de $M$. javanica $(\mathrm{FR}=\mathrm{Pf} / \mathrm{Pi})$ na época chuvosa variaram de 4 na cultivar Edzina a 87 na cultivar Christa, não diferindo estatisticamente, porém foi até 43 vezes superior aos fatores de reprodução do nematóide no experimento de época seca (Tabela 1). A ocorrência de temperaturas mais elevadas, registradas a $20 \mathrm{~cm}$ de profundidade $(27,0$ $33,0^{\circ} \mathrm{C}$ ), na época chuvosa, contribuíram para a elevação do FR de $M$. javanica nos genótipos de batata. Em conseqüência, as produtividades na época chuvosa foram reduzidas de $7 \%$ a $46 \%$ em cultivares nacionais, e de $9 \%$ a $64 \%$ em cultivares importadas, comprovando, assim, maiores perdas nesta época de plantio (Tabela 1). As cultivares Claudia, Edzina e Sowa, com as menores produtividades $(3,5$ a $4,5 \mathrm{t} / \mathrm{ha}$ ) no experimento de época seca, mantiveram as mesmas produtividades no experimento de época chuvosa, sendo, portanto, consideradas como as cultivares menos produtivas entre todos os genótipos de batata avaliados.

As porcentagens de infecção de tubérculos comerciais na época chuvosa variaram de $31,0 \%$ na cultivar Achat a 93,5\% na cultivar Delta-S, com diferença significativa somente entre a cultivar Achat, com resistência moderada, e as cultivares com suscetibilidade alta a $M$. javanica (Tabela 1). Não foi possível observar diferença significativa em porcentagens de infecção de tubérculos comerciais, através do teste de médias de Student-Newman-Keuls (SNK) entre os outros genótipos de batata na época chuvosa (Tabela 1).

A análise multivariada possibilitou a separação dos genótipos em quatro grupos distintos, segundo as porcentagens de infecção de tubérculos comerciais: genótipos com resistência moderada (RM) - um genótipo, cultivar Achat, com porcentagem de infecção de tubérculos de, no máximo, 31,0\%; genótipos com suscetibilidade moderada (SM) -15 genótipos, com porcentagens de infecção entre 35,5\% e 42,2\%; genótipos suscetíveis (S) - 17 genótipos, com porcentagens de infecção entre $44,5 \%$ e $62,9 \%$, e genótipos com suscetibilidade alta (SA) - 15 genótipos, com porcentagens de infecção entre $65,0 \%$ e $93,5 \%$ (Tabela 1). Entre os genótipos de batata avaliados em campo, não se observou nível alto de resistência a $M$. javanica.

A época seca não foi adequada para a avaliação de resistência porque a baixa temperatura do solo retardou o aparecimento do sintoma de galhas nos tubérculos, mesmo em cultivares de comprovada suscetibilidade como 'Baronesa' e 'Bintje'. Entre outros fatores, a baixa incidência de nematóides faz com que o plantio de batata no Distrito Federal seja concentrado nesta época.

A obtenção de genótipos de batata resistentes à infecção por nematóides permitirá a expansão da época de plantio para períodos mais quentes do ano. Além de reduzir os danos diretos aos tubérculos, a resistência aos nematóides das galhas é essencial como medida auxiliar no controle da murcha-bacteriana, pois está bem estabelecido que Ralstonia solanacearum, agente causal da murcha-bacteriana, penetra por ferimentos causados por nematóides (Jatala et al., 1988). 
Tabela 1. Reação de genótipos de batata à infecção por Meloidogyne javanica em épocas seca e chuvosa no Distrito Federal, 1997

\begin{tabular}{|c|c|c|c|c|c|c|c|c|c|c|c|}
\hline \multirow[t]{2}{*}{ Genótipo } & \multicolumn{5}{|c|}{ Época seca } & \multicolumn{6}{|c|}{ Época chuvosa } \\
\hline & $\mathrm{Pi}$ & $\mathrm{Pf}$ & $\begin{array}{l}\mathrm{Pf} / \mathrm{Pi}^{(1)} \\
(\mathrm{FR})\end{array}$ & $\begin{array}{c}\text { Produção } \\
\text { (t/ha) }\end{array}$ & $\begin{array}{c}\text { Infecção }^{(2)} \\
(\%)\end{array}$ & $\mathrm{Pi}$ & Pf & $\begin{array}{l}\mathrm{Pf} / \mathrm{Pi} \\
(\mathrm{FR})\end{array}$ & $\begin{array}{c}\text { Produção } \\
\text { (t/ha) }\end{array}$ & $\begin{array}{c}\text { Infecção } \\
(\%)\end{array}$ & $\operatorname{Reação~}^{(3)}$ \\
\hline Achat & $6^{\mathrm{ns}}$ & $60^{\mathrm{ns}}$ & $10^{\mathrm{ns}}$ & $10,5^{*}$ & $1,0^{\mathrm{ns}}$ & $4^{\mathrm{ns}}$ & $100^{\mathrm{ns}}$ & $25^{\mathrm{ns}}$ & $5,5^{\mathrm{ns}}$ & 31,0 & RM \\
\hline Uran & 4 & 16 & 4 & $16,0^{*}$ & 1,2 & 12 & 552 & 46 & 9,0 & 35,5 & SM \\
\hline Monalisa & 4 & 8 & 2 & $14,0 *$ & 0,0 & 32 & 256 & 8 & 10,0 & 35,7 & SM \\
\hline Edzina & 3 & 33 & 11 & 3,5 & 0,9 & 19 & 76 & 4 & 3,5 & 36,0 & SM \\
\hline Berolina & 3 & 18 & 6 & $11,0 *$ & 0,9 & 17 & 102 & 6 & 9,0 & 37,5 & SM \\
\hline Claudia & 2 & 36 & 18 & 4,0 & 0,0 & 7 & 119 & 17 & 4,0 & 37,6 & SM \\
\hline Granola & 2 & 28 & 14 & $11,0^{*}$ & 0,0 & 22 & 484 & 22 & 9,5 & 37,7 & SM \\
\hline Christa & 5 & 10 & 2 & 6,5 & 0,0 & 10 & 870 & 87 & 5,5 & 38,8 & $\mathrm{SM}$ \\
\hline Linda & 2 & 32 & 16 & 10,0 & 0,7 & 33 & 528 & 16 & 6,5 & 39,0 & $\mathrm{SM}$ \\
\hline Desiree & 2 & 18 & 9 & 7,0 & 0,0 & 22 & 968 & 44 & 5,0 & 39,1 & $\mathrm{SM}$ \\
\hline Renska & 3 & 18 & 6 & 5,5 & 0,0 & 16 & 256 & 16 & 5,0 & 39,2 & $\mathrm{SM}$ \\
\hline Eureka & 2 & 18 & 9 & 8,0 & 7,3 & 23 & 874 & 38 & 8,0 & 39,7 & SM \\
\hline Recent & 2 & 4 & 2 & 10,0 & 0,0 & 87 & 696 & 8 & 6,0 & 40,7 & $\mathrm{SM}$ \\
\hline Nordstern & 3 & 18 & 6 & $14,0^{*}$ & 0,2 & 41 & 697 & 17 & 7,0 & 41,1 & $\mathrm{SM}$ \\
\hline Santo Amor & 3 & 69 & 23 & 10,0 & 0,0 & 32 & 768 & 24 & 8,0 & 41,5 & SM \\
\hline Podzola & 7 & 14 & 2 & 7,0 & 0,0 & 31 & 310 & 10 & 4,0 & 42,2 & SM \\
\hline Tarpan & 4 & 80 & 20 & 7,0 & 0,0 & 27 & 432 & 16 & 3,0 & 44,5 & $\mathrm{~S}$ \\
\hline Vokal & 2 & 8 & 4 & 10,0 & 0,0 & 21 & 273 & 13 & 7,0 & 45,5 & $\mathrm{~S}$ \\
\hline Clone 88 & 2 & 62 & 31 & $11,0^{*}$ & 0,0 & 30 & 420 & 14 & 6,5 & 46,1 & $\mathrm{~S}$ \\
\hline Univita & 3 & 21 & 7 & $14,0 *$ & 0,7 & 31 & 713 & 23 & 5,0 & 48,5 & $\mathrm{~S}$ \\
\hline Clone 70 & 5 & 45 & 9 & $17,0^{*}$ & 0,0 & 13 & 169 & 13 & 8,5 & 49,0 & $\mathrm{~S}$ \\
\hline Diamant & 2 & 66 & 33 & 5,5 & 0,0 & 23 & 851 & 37 & 5,0 & 50,0 & $\mathrm{~S}$ \\
\hline Gloria & 5 & 40 & 8 & 8,0 & 7,0 & 34 & 714 & 21 & 5,0 & 50,2 & $\mathrm{~S}$ \\
\hline Alpha & 2 & 36 & 18 & 6,0 & 0,0 & 12 & 876 & 73 & 3,5 & 50,8 & $\mathrm{~S}$ \\
\hline Belladona & 4 & 52 & 13 & 6,5 & 0,0 & 11 & 198 & 18 & 5,5 & 55,7 & $\mathrm{~S}$ \\
\hline Aracy & 2 & 16 & 8 & 7,0 & 0,0 & 14 & 294 & 21 & 4,5 & 56,7 & $\mathrm{~S}$ \\
\hline Duvira & 2 & 26 & 13 & 5,0 & 5,8 & 29 & 348 & 12 & 2,5 & 57,6 & $\mathrm{~S}$ \\
\hline Hertha & 2 & 64 & 32 & $11,5^{*}$ & 0,3 & 31 & 806 & 26 & 7,0 & 57,9 & $\mathrm{~S}$ \\
\hline Jatte-Bintje & 2 & 12 & 6 & $11,0^{*}$ & 2,6 & 18 & 324 & 18 & 5,5 & 59,5 & $\mathrm{~S}$ \\
\hline Chiquita & 3 & 84 & 28 & $13,0 *$ & 1,3 & 16 & 912 & 57 & 7,5 & 60,2 & $\mathrm{~S}$ \\
\hline Nicola & 3 & 48 & 16 & $10,5^{*}$ & 1,9 & 21 & 882 & 42 & 8,0 & 62,0 & $\mathrm{~S}$ \\
\hline Anosta & 2 & 38 & 19 & $14,0 *$ & 0,0 & 40 & 400 & 10 & 5,5 & 62,6 & $\mathrm{~S}$ \\
\hline Culpa & 2 & 48 & 24 & 9,5 & 0,0 & 50 & 500 & 10 & 7,5 & 62,9 & $\mathrm{~S}$ \\
\hline Clone 27 & 5 & 35 & 7 & 10,0 & 0,0 & 61 & 305 & 5 & 6,5 & 65,0 & SA \\
\hline Vittorini & 6 & 18 & 3 & $11,0^{*}$ & 9,7 & 70 & 980 & 14 & 7,0 & 67,1 & SA \\
\hline Mantiqueira & 4 & 12 & 3 & $13,0^{*}$ & 4,0 & 38 & 950 & 25 & 7,0 & 67,2 & SA \\
\hline Mineira & 2 & 4 & 2 & 7,0 & 2,4 & 42 & 588 & 14 & 6,5 & 69,4 & SA \\
\hline Maria & 2 & 12 & 6 & 10,0 & 3,1 & 21 & 735 & 35 & 6,0 & 69,9 & SA \\
\hline Baronesa & 2 & 12 & 6 & $11,5^{*}$ & 1,5 & 79 & 553 & 7 & 7,0 & 70,1 & SA \\
\hline Lenino & 3 & 66 & 22 & 9,0 & 5,1 & 11 & 704 & 64 & 8,0 & 71,5 & SA \\
\hline Bintje-C & 2 & 42 & 21 & $12,0^{*}$ & 2,3 & 87 & 696 & 8 & 7,0 & 73,5 & SA \\
\hline Steffi & 2 & 20 & 10 & 7,0 & 0,0 & 35 & 525 & 15 & 3,0 & 74,5 & SA \\
\hline Grata & 2 & 14 & 7 & 9,0 & 0,3 & 13 & 572 & 44 & 7,0 & 75,0 & SA \\
\hline Sabina & 4 & 28 & 7 & 7,5 & 0,4 & 32 & 608 & 19 & 3,0 & 76,8 & SA \\
\hline Elvira & 2 & 8 & 4 & $10,5^{*}$ & 3,5 & 19 & 836 & 44 & 8,5 & 80,4 & SA \\
\hline Sowa & 5 & 20 & 4 & 4,5 & 0,0 & 61 & 671 & 11 & 4,5 & 81,7 & SA \\
\hline Grandifolia & 4 & 60 & 15 & 7,0 & 8,9 & 18 & 828 & 46 & 4,5 & 89,3 & SA \\
\hline Delta-S & 3 & 72 & 24 & 7,0 & 0,0 & 14 & 994 & 71 & 5,5 & 93,5 & SA \\
\hline C.V. (\%) & 39,0 & 43,0 & 46,0 & 31,0 & 26,0 & 41,0 & 40,0 & 44,0 & 25,0 & 28,0 & - \\
\hline
\end{tabular}

(1)Pf/Pi: relação população final (Pf)/população inicial (Pi), determinadas pelo número de segundo estádio juvenil (J2) de amostras de $200 \mathrm{~mL}$ de solo = fator de reprodução do nematóide (FR); médias de quatro repetições, dados transformados para log (x+1). (2)Porcentagens (\%) do peso de tubérculos comerciais infectados por M. javanica. ${ }^{(3)}$ Reação: RM: resistência moderada; SM: suscetibilidade moderada; S: suscetivel; SA: suscetibilidade alta. ${ }^{n s}$ Nãosignificativo. *Significativo pelo teste de Student-Newman-Keuls (SNK) a 5\% de probabilidade. 
As cultivares Eureka, Gloria, Grandifolia e Vittorini foram as mais suscetíveis à infecção por $M$. javanica na época seca, que mostraram sintomas de galhas, com infecção de tubérculos de $7,0 \%$ a $9,7 \%$, mesmo com baixas temperaturas do solo. No experimento de época chuvosa, essas cultivares tiveram porcentagens de infecção de cinco a dez vezes maior que as obtidas no experimento de época seca, em conseqüência da elevação de temperatura do solo (Tabela 1).

$\mathrm{Na}$ época seca, a produção de tubérculos comerciais foi de boa qualidade, em virtude da não-incidência de chuvas, que possibilitou maior potencial produtivo dos genótipos de batata. Os resultados dos experimentos de época seca foram incluídos no trabalho para comparação com os resultados de época chuvosa, considerando que na época chuvosa a produtividade dos genótipos de batata foi reduzida em conseqüência da alta incidência por $M$. javanica, ocasionada por altas temperaturas (Tabela 1).

A época chuvosa, mesmo considerando a redução de produtividade dos genótipos de batata, que variou de $7 \%$ a $64 \%$, foi mais adequada para avaliação de resistência ou suscetibilidade dos genótipos à infecção por M. javanica no campo. As principais cultivares de batata plantadas no Brasil são de alta suscetibilidade à infecção por $M$. javanica, o que torna necessária a aplicação de nematicidas nesta época de cultivo. São usualmente aplicados de 25 a $30 \mathrm{~kg} / \mathrm{ha}$ de nematicida Aldicarb ou de 60 a $80 \mathrm{~kg} / \mathrm{ha}$ de nematicida Carbofuran para obter a produção média de 10 t/ha de tubérculos comerciais de batata, livres da infecção por nematóides na época chuvosa.

As cultivares Berolina, Elvira, Granola, Nicola e Monalisa com produtividade média acima de $10 \mathrm{t} / \mathrm{ha}$ na época seca e com redução de produtividade inferior a $30 \%$ na época chuvosa, terão boas perspectivas de produção se o controle químico de $M$. javanica for feito na época chuvosa. Os demais genótipos avaliados não são recomendados para plantio na época chuvosa.

As cultivares Uran, Monalisa, Edzina, Berolina, Claudia e Granola, de suscetibilidade moderada (SM) a $M$. javanica, com porcentagens de infecção de tubérculos que variaram de $35,5 \%$ a $37,7 \%$, próximas de 'Achat', de resistência moderada (RM), com $31,0 \%$ de infecção neste trabalho, apresentaram in- fecção por $M$. incognita de $36,6 \%$ a 59,2\% no trabalho conduzido por Charchar \& Moita (1996). Da mesma forma, o Clone 70 e as cultivares Sowa, Steffi, Sabina e Vittorini pertencentes ao grupo de 'Achat' (RM) no trabalho de Charchar \& Moita (1996), com infecções de $25,4 \%$ a $33,1 \%$, obtiveram de $49,0 \%$ a $81,7 \%$ de infecção por $M$. javanica neste trabalho. Esses genótipos não podem ser utilizados como progenitores em programas de melhoramento, considerando a reação diferenciada à infecção por M. javanica e $M$. incognita, já que no Brasil a mistura dessas espécies está amplamente disseminada em áreas de produção de batata. De outra forma, esses genótipos só podem ser recomendados para plantio em áreas infestadas se o controle químico com o uso de nematicidas registrados for utilizado.

Em trabalhos anteriores, a cultivar Achat apresentou também resistência moderada a $M$. incognita (Charchar \& Moita, 1996) e à população mista de M. incognita e M. javanica (Charchar \& Moita, 1997). Mas o não-florescimento de 'Achat' dificulta sua utilização em programas de melhoramento. Por outro lado, a cultivar Berolina, com suscetibilidade moderada à infecção por $M$. javanica com $37,5 \%$ de infecção de tubérculos neste trabalho, teve a mesma reação por $M$. incognita com $36,6 \%$ de infecção no trabalho anterior (Charchar \& Moita, 1996), e tem potencial para ser utilizada como progenitor em programas de melhoramento de batata, considerando que seu florescimento não é difícil.

Novas fontes de resistência em batata à infecção por nematóides-das-galhas serão no futuro avaliadas com a utilização de espécies silvestres do gênero Solanum, tendo em vista o baixo nível de resistência apresentado por cultivares nacionais e importadas de batata plantadas no Brasil.

\section{Conclusões}

1. A cultivar Achat é a mais resistente à infecção por M. javanica durante a época chuvosa.

2. A cultivar Achat não floresce, por isso não pode ser recomendada como progenitor; porém, a cultivar Berolina, com suscetibilidade moderada às espécies M. javanica e M. incognita na época chuvosa, é recomendada como progenitor em programas de melhoramento. 
3. É baixa a resistência das cultivares de batata comerciais às espécies $M$. javanica e $M$. incognita.

4. A avaliação da resistência de genótipos de batata a Meloidogyne javanica deve ser feita na época chuvosa; nesta época a infecção é superior à observada na época seca.

\section{Referências}

CHARCHAR, J. M. Meloidogyne em hortaliças. In: CONGRESSO INTERNACIONAL DE NEMATOLOGIA TROPICAL, 19., 1995, Rio Quente. Programa e anais.. Brasília : Sociedade Brasileira de Nematologia, 1995. p. 149-153.

CHARCHAR, J. M. Nematóides de importância para a cultura da batata. Informe Agropecuário, Belo Horizonte, v. 7, n. 76 , p. $50-54,1981$

CHARCHAR, J. M. Nematóides fitoparasitas associados à cultura da batata nas principais regiões de produção do Brasil. Nematologia Brasileira, Piracicaba, v. 21, n. 2, p. 49-60, 1997.

CHARCHAR, J. M.; MOITA, A. W. Reação de cultivares de batata à infecção por Meloidogyne incognita raça 1 . Horticultura Brasileira, Brasília, v. 14, n. 2, p. 189-193, 1996

CHARCHAR, J. M.; MOITA, A. W. Reação de cultivares de batata a uma infestação mista de Meloidogyne incognita raça 1 e $M$. javanica. Nematologia Brasileira, Piracicaba, v. 21, n. 1, p. 39-48, 1997.

FLEGG, J. J.; HOOPER, D. J. Extraction of free-living stages from soil. In: SOUTHEY, J. F. (Ed.). Laboratory methods for working with plant and soil nematodes. London : Ministry of Agriculture, Fisheries and Food, 1970. 148 p. (Technical Bulletin, 2)

GRECO, N. Nematode problems affecting potato production in subtropical climates. Nematropica, Auburn, v. 23 , n. 2 , p. $213-220,1993$

JATALA, P.; MARTIN, C.; MENDOZA, A. Role of nematodes in disease expression by Pseudomonas solanacearum and strategies for screening and breeding for combined resistance. In: PLANNING CONFERENCE ON BACTERIAL DISEASES OF THE POTATO, 1987, Lima. Report... Lima : Centro Internacional de La Papa, 1988. p. 35-37.

JENKINS, W. R. A rapid centrifugal flotation technique for separating nematode from soil. Plant Disease Reporter, Beltsville, v. 48, p. 62, 1964.

SOKAL, R. R.; MICHENER, C. D. A statistical method for evaluation systematic relationships. University of Kansas Science Bulletin, Lawrence, v. 38, p. 1409-1438, 1958

WEINGARTNER, D. F.; McSORLEY, R.; GOTH, R. W. Management strategies in potato for nematodes and soilbornes diseases in subtropical Florida. Nematropica, Auburn, v. 23, n. 2, p. 233-245, 1993.

ZEM,A. C.; ZANNON, J. I.; LORDELLO, L. G. E. Doses e épocas de aplicação do nematicida Carbofuran no controle de Meloidogyne javanica na cultura da batata (Solanum tuberosum L.). In: REUNIÃO DE NEMATOLOGIA, 5., 1981, Londrina. Trabalhos apresentados... Piracicaba : Sociedade Brasileira de Nematologia, 1982. p. 233-245. 